\title{
Perceived Social Support and Psychological Well-Being: Testing the Unique Association and Gender Differences among
}

\author{
Young Working Adults
}

\author{
Kalpana Rani $E^{1 *}$
}

\section{ABSTRACT}

The purpose of the current study was (i) to find out the association between Perceived Social Support (PSS) and Psychological Well-Being (PWB) among young working adults and (ii) to study Gender differences in this relationship. 286 individuals volunteered to participate in the study within age range between 21 to 28 years. The sample consisted of 173 males and 113 females who were currently employed. PSS was measured using Multidimensional Scale of Perceived Social Support and PWB by Ryff's Scale of Psychological Well-Being. The data was analysed using independent samples ' $\mathrm{t}$ ' test, Pearson Product Moment Correlation analysis and Regression analysis. The results indicated that PSS has a significant positive correlation with PWB indicating that the higher the level of PSS, the higher the level of PWB. Further, significant gender differences were found in PSS, with women reporting receiving more social support than men and women were also high in support from two of the three types of sources: family and friends. In addition, both men and women reported availability of higher social support from family as compared to what they can obtain from friends and significant other. No significant gender differences were found in PWB. Regression analysis indicated that PSS could significantly contribute to the prediction of PWB accounting for about twelve percent variance in it. Besides, PSS explained relatively higher variance in PWB among men as compared to women. Positive relations and self acceptance dimensions of PWB were better influenced by PSS in both men and women.

Keywords: Perceived social support, Psychological well-being, Gender, Young working adults.

Over the years, there is an unprecedented increase in the threat to human psyche due to diminishing family bonds, reduced family size, unsteady nature of interpersonal interactions, fierce competition among peers, disintegration of societal values, crime and violence, global

\footnotetext{
${ }^{1}$ Defence R\&D, Min of Def, DRDO, India

*Responding Author

(C) 2016 I K Rani; licensee IJIP. This is an Open Access Research distributed under the terms of the Creative Commons Attribution License (http://creativecommons.org/licenses/by/2.0), which permits unrestricted use, distribution, and reproduction in any Medium, provided the original work is properly cited.
} 


\section{Perceived Social Support and Psychological Well-Being: Testing the Unique Association and Gender Differences among Young Working Adults}

terrorism etc. Despite the fact that stress increasingly touches the life of almost all sections of the people, young adults are more likely than others to bear the brunt of present day challenges.. Among young adults, the major area that contributes to their stress is work. Some of the workrelated issues that are being faced by them are job insecurity, career challenges, high aspirations and peer pressures. In addition, high expectations from family, changing role and responsibilities, changing nature of friendships and intimate relationships, societal demands for marriage and forming a family etc are contributors to their stress.

Typically the period between 18-25 is defined as the period of young adulthood. However, research suggests that the transition to adulthood now typically takes longer than in previous times/generations, especially in industrialized societies due to prolonged periods of exploration in education and employment and at same time, delaying marriage and stability in life (Rindfuss, 1991).

In an analysis of workplace stress, the study investigated the levels of social support, work strain and psychological distress among both men and women (Vermeulen \& Mustard, 2000). It was found that low social support was associated with higher distress across all categories of job strain, and the combined effect of low social support and high job strain was associated with the greatest increase in distress. It suggests that the strong social support network can be critical to help young individuals cope well in these tough times.

In a study conducted by Arnett, J.J. (2000), 300 young people between the ages of 18 and 29 were asked to report the emotions and feelings they experienced while on the threshold of adulthood. Arnett surveyed individuals from all over the world, and found that the challenges of young adults are overwhelming and they desire for remaining closely linked to one's family, in order to obtain support in spite of their need to achieve independence. Research studies have shown that increase or onset of psychological problems in young people may be prevented by social support from parents, siblings, members of the extended family, and peers (Walen \& Lachman, 2000; Whitney, 2010).

The knowledge that we are accepted, respected, loved, supported, that there are people that we can lean on and get help from, affects self-esteem and self-image. Past research has shown that people who receive high social support are more likely to be insulated from problems they have in life and thus less likely to be driven to extreme actions/reactions. In other words, although social support primarily has the role of "bumper" which mitigates the effect of stressful life events, it is also a very important source of strength to quickly and with less bad consequences, overcome the most difficult life situations (Vlajkovi, 1992). A significant body of research showed that social contact serves as a resilience-promoting factor. 


\section{Perceived Social Support and Psychological Well-Being: Testing the Unique Association and Gender Differences among Young Working Adults}

Unlike west, the role of social support is distinct in India. As collective society, family members provide lot of support on an unconditional basis. The family supports the old; takes care of widows, never-married adults, assists during periods of unemployment; and provides security and a sense of support and togetherness (Chekki 1996; Sethi 1989). In spite of the numerous changes and adaptations to a pseudo-Western culture and a move toward the nuclear family among the middle and upper classes, the Indian family still continues to be a dominant institution in the life of the individual and in the life of the community (Mullatti, 1992). Research studies have repeatedly found that people who receive a high level of social support enjoy enhanced health and well-being (Cohen \& Wills, 1985; Sarason, Sarason, \& Gurung, 2001).

Over time, social support has come to possess different dimensions and is expressed in different forms and different ways. Of all the constructs, perceived support has been regarded as consistently linked to health. Perceived support is the subjective judgment of how much the individuals perceive that they are supported by family or peer groups. Research has also indicated that perceived support is a better predictor of psychological well-being than the actual support received (Cohen et al., 2000; Gallagher \& Vella-Brodrick, 2008)

Social support has been extensively studied and is thought to influence well- being by modifying and buffering the impact of life events and other stressors [Pugliesi and Shook (1998); Southwick SM, Vythilingam M, Charney DS (2005)]. Social ties are being increasingly linked to longevity, lower stress levels and improved overall well-being. Psychological well-being (PWB), as summed by Huppert (2009), is about lives going well. It is the combination of feeling good and functioning effectively. The concept of feeling good incorporates not only the positive emotions of happiness and contentment, but also such emotions as interest, engagement, confidence, and affection. In a psychological sense, the concept of functioning effectively involves the development of one's potential, having some control over one's life, having a sense of purpose in life in terms of working towards valued goals, and experiencing positive relationships. By definition, people with high PWB report feeling happy, capable, wellsupported, satisfied with life, and so on; A large body of cross-sectional survey data shows that happy people: tend to function better in life than less happy people; are typically more productive and more socially engaged; and tend to have higher incomes (Diener, 2000; Judge, Thoresen, Bono, \& Patton, 2001). Well-being integrates mental health (mind) and physical health (body) resulting in more holistic approaches to disease prevention and health promotion. PWB is increasingly being recognized as an indicator of societal success and is receiving great attention in last few decades among policymakers both nationally and internationally (Dolan, Layard \& Metcalfe, 2011).

The need for individual wellbeing has never been more critical for young adults given the current and projected challenges in this threatening and rapidly changing world. Towards this end, it is necessary to make every possible effort to examine the factors that may help them face the 
challenges of the modern world which also enable them to be productive at work and also promote their well-being to enable them to . There is ample research evidence to suggest that social support has an important influence on outcomes across the lifespan; and among various age groups. Social support is an aspect that should be reviewed since it is described as both a buffer against life stressors as well as an agent promoting health and wellness (Dollete, Steese, Phillips, \& Matthews, 2004).However, there is scant research on the role of social support in the wellbeing of young adults who are in the transition from young adulthood to independent adult. Therefore, there is a need to explore the role of PSS in the well-being to gain a greater understanding about its role in contributing to PWB.

So far, most of such studies have been conducted in Western countries and it is not clearly demonstrated whether the findings can be generalized to other cultures as well (Chen, He, Oliveria, Coco, et al., 2004). Besides, such studies are conducted on the total populations by combining males and females. However, research evidence shows that social support is generally perceived differently among males and females (Mahaffy, 2004, Sharir, Tanasescu, Turbow and Maman 2007). Numerous studies have reported gender differences in the exposure and reactivity to stressors and social support, giving rise to the assumption that the pathogenic effect of these factors is different for males and females (Cyranowski et al., 2000; Garber \& Flynn, 2001). The findings of such research on gender differences in perceived social support, however, are not conclusive. The present study addresses these important gaps in knowledge. Towards this end, the study has two main objectives. Firstly, to find out how well Perceived Social Support (PSS) predicts Psychological Well-Being (PWB) among young working adults and then to explore gender differences in this relationship.

\section{PRESENT STUDY}

Aim

The aim of the present study was to examine the association between Perceived Social Support (PSS) and Psychological Well-Being (PWB) among young working adults in India and to explore gender differences in the relationship between these two variables. The specific objectives of the study were,

- To find out how well PSS predicts the PWB in young working adults.

- To find out the level of perceived social support reported by young working men and women in India.

- To compare the perceived social support of young working men and women.

- To examine the impact of gender differences in the relationship between PSS on PWB 


\section{METHOD}

\section{Participants:}

The sample for the study consisted of 286 young working adults in the age range of 21 to 28 years (SD 1.29). Out of 286, 173 (60.5\%) were men in the age range of 21 to 27 with a mean of 23.51 years (SD 1.27) and 113 (39.5\%) were women age ranging between 21 to 28 years and their mean age was 23.34 years (SD 1.33). All the participants had graduation as minimum educational qualification and were employed.

\section{Measures:}

\section{The Multidimensional Scale of Perceived Social Support (Zimet, Dahlem, Zimet \& Farley, 1988)}

The Multidimensional Scale of Perceived Social support (MSPSS) was developed by Zimet, Dahlem, Zimet, and Farley (1988). It consists of 12 items to identify the soical support factors perceived by the individuals. The scale is comprised of 3 groups depending on the source of support, each group consisting of 4 items. These are family, friends and special person. Each item is rated using a 7 point range scale varying between “definitely no" and “definitely yes”. The sum of 4 items under each sub-scale gives the sub-scale score, while the sum of all sub-scale scores gives the overall scale score. The lowest score in sub-scales is 4 , and the highest is 28 . The lowest overall scale score is 12 and the highest is 84 . MSPSS captures multiple aspects of perceived social support, across three major sources of support (Family, Friends or Significant Others) and social desirability effects have been examined and were found to be insignificant (Dahlem, Zimet, \& Walker, 1991). High scores reflect more perceived social support. The PSS has an excellent internal consistency, with an alpha of .90 .

\section{The Ryff's Scales of Psychological Well Being (Ryff 1989)}

The Ryff's Scales of Psychological Well-Being is a theoretically sound instrument that focuses on measuring multiple aspects of PWB (SPWB, Ryff, 1989). The 42 items instrument consists of six subscales: (a) Positive Relations with Others is quality relationships with friends, lovers, and other people in one's life. (b) Self-Acceptance is the positive evaluation of oneself and ones past life. (c) Autonomy is self-determination and control. (d) Environmental Mastery is effectively managing one's life and the surrounding world. (e) Personal Growth is the sense that one is growing and developing as a person. Finally, (f) Purpose in Life is the belief that one's life has purpose and meaning. This six-dimensional conceptualization has garnered considerable support and acceptance by the experts in the field structure (Abbott et al. 2006; Springer and Hauser 2006; Ryff and Keyes 1995 ) which suggests that it is a better standard measure of PWB. Each subscale consists of 7 items and participants respond on a 6- point scale that ranges from "strongly disagree" (1) to "strongly agree" (6). Responses are totaled for each of the six attributes. The reliability and validity of the SPWB was found to be reasonably satisfactory 


\section{Statistical Analyses}

To achieve the objectives of the study, the data were analyzed using inferential statistics, specifically ' $t$ ' test to examine gender differences, Pearson correlation coefficients to assess bivariate relationships and regression analysis to study causal association between predictor and criterion variable. The statistical analysis was conducted by using the software SPSS version 18.0.

\section{RESULTS}

\section{Descriptive statistics}

Table 1 presents means and standard deviations of the different variables for males and females separately.

Table 1 Descriptive statistics for PSS and PWB variables for males and females

\begin{tabular}{|c|c|c|c|c|c|c|c|}
\hline \multirow[t]{2}{*}{ Variables } & \multicolumn{2}{|c|}{$\begin{array}{l}\text { Total sample } \\
(\mathrm{N}=286)\end{array}$} & \multicolumn{2}{|c|}{ Men (n=173) } & \multicolumn{2}{|c|}{ Women (n=113) } & \multirow[t]{2}{*}{ 't' value } \\
\hline & $\begin{array}{l}\text { Mean } \\
\text { Score }\end{array}$ & SD & $\begin{array}{l}\text { Mean } \\
\text { Score }\end{array}$ & SD & $\begin{array}{l}\text { Mean } \\
\text { Score }\end{array}$ & SD & \\
\hline PSS & 71.73 & 9.70 & 70.16 & 9.69 & 74.12 & 9.26 & $-3.44 * *$ \\
\hline Signi Other & 22.82 & 5.23 & 22.39 & 5.08 & 23.47 & 5.40 & $-1.71 \mathrm{~ns}$ \\
\hline Friends & 24.13 & 3.43 & 23.61 & 3.55 & 24.92 & 3.07 & $-3.21 * *$ \\
\hline Family & 24.78 & 3.12 & 24.16 & 3.09 & 25.73 & 2.94 & $-4.30 * *$ \\
\hline PWB & 198.45 & 20.75 & 199.42 & 20.77 & 196.96 & 20.73 & $.98 \mathrm{~ns}$ \\
\hline Autonomy & 31.01 & 4.34 & 30.99 & 4.45 & 31.04 & 4.20 & $-.09 \mathrm{~ns}$ \\
\hline $\begin{array}{l}\text { Envt } \\
\text { Mastery }\end{array}$ & 30.61 & 3.46 & 30.68 & 3.53 & 30.50 & 3.36 & $.42 \mathrm{~ns}$ \\
\hline $\begin{array}{l}\text { Personal } \\
\text { Growth }\end{array}$ & 35.05 & 4.69 & 35.51 & 4.51 & 34.35 & 4.88 & $2.07 *$ \\
\hline $\begin{array}{l}\text { Positive } \\
\text { Relations }\end{array}$ & 35.16 & 4.83 & 35.27 & 4.89 & 35.01 & 4.76 & $.44 \mathrm{~ns}$ \\
\hline $\begin{array}{l}\text { Purpose in } \\
\text { Life }\end{array}$ & 32.94 & 4.54 & 33.30 & 4.55 & 32.38 & 4.49 & $1.68 \mathrm{~ns}$ \\
\hline $\begin{array}{l}\text { Self } \\
\text { Acceptance }\end{array}$ & 33.68 & 4.90 & 33.68 & 5.05 & 33.69 & 4.67 & $-.02 \mathrm{~ns}$ \\
\hline
\end{tabular}

$$
* * p<.01, * p<.05
$$

The descriptive statistics presented in the table included the mean and standard deviation of all the study variables. The obtained mean scores indicate, given the possible range of scores for each scale, that the young working adults participated in this study, in general, reported above 
average values on all the variables of the study. Besides, the present study revealed mean differences between male and female participants in PSS and PWB. Additionally, in terms of mean values, the support perceived from family was higher as compared to the support obtained from friends and significant other by both males and females in the study. These results suggest that the young working males and females in present study perceived family provide them with more support as compared to what they can obtain from friends and significant other. For both males and females, the mean scores on personal growth and positive relations were found higher as compared to self acceptance and purpose in life, and both the groups obtained lowest mean scores on autonomy and environmental mastery dimensions.

To test whether there are any significant gender differences, differences in mean values between men and women on PSS and its sub-scales were tested for statistical significance using independent samples t-test. Result of the t-test showed there was significant difference between males and females in PSS ( $\mathrm{t}=3.44, \mathrm{p}<0.01)$. Females scored higher in PSS (74.12) than males (70.16) indicating that females perceived significantly more social support as compared with males counterparts. Further, while women perceived significantly more support from family $(4.30, \mathrm{p}<.01)$ and friends $(3.21, \mathrm{p}<.01)$ than men, the difference in perception of significant other support was non-significant (1.71).

The obtained ' $t$ ' values in respect of PWB and its sub-dimensions, in contrast, did not show significant gender differences, except in personal growth, wherein men showed significantly high mean value as compared to women $(\mathrm{t}=2.07, \mathrm{p}<.05)$.

\section{Bivariate correlations}

Table 2 shows the results of correlation coefficients computed between dimensions of PSS and facets of PWB for total sample.

Table 2: Bivariate correlations between PSS and PWB (N-286)

\begin{tabular}{|l|l|l|l|l|l|l|l|}
\hline Variable & Autonomy & $\begin{array}{l}\text { Envt } \\
\text { mastery }\end{array}$ & $\begin{array}{l}\text { Personal } \\
\text { growth }\end{array}$ & $\begin{array}{l}\text { Positive } \\
\text { relations }\end{array}$ & $\begin{array}{l}\text { Purpose } \\
\text { in life }\end{array}$ & $\begin{array}{l}\text { Self } \\
\text { acceptance }\end{array}$ & $\begin{array}{l}\text { Overall } \\
\text { PWB }\end{array}$ \\
\hline Sig. other & $.19^{* *}$ & $.15^{* *}$ & $.13^{*}$ & $.35^{* *}$ & $.14^{* *}$ & $.25^{* *}$ & $.26^{* *}$ \\
\hline Friends & $.21^{* *}$ & $.14^{* *}$ & $.16^{* *}$ & $.40^{* *}$ & $.21^{* *}$ & $.28^{* *}$ & $.31^{* *}$ \\
\hline Family & $.15^{* *}$ & $.18^{* *}$ & $.08 \mathrm{~ns}$ & $.29^{* *}$ & $.18^{* *}$ & $.30^{* *}$ & $.26^{* *}$ \\
\hline $\begin{array}{l}\text { Overall } \\
\text { PSS }\end{array}$ & $.22^{* *}$ & $.19^{* *}$ & $.15^{* *}$ & $.43^{* *}$ & $.21^{* *}$ & $.33^{* *}$ & $.34^{* *}$ \\
\hline
\end{tabular}

$*^{*}-p<.01,{ }^{*}-p<.05$ 


\subsection{Relationship between PSS and PWB}

The results of correlation analysis showed a moderate significant positive relationship between PSS and PWB ( $r=.34, \mathrm{p}<.01)$ for the total sample suggesting that a high perception of social support is associated with PWB. The relationship between friends and PWB was found highest (.31, $\mathrm{p}<.01)$, followed by both significant other $(.26, \mathrm{p}<.01)$ and family $(.26, \mathrm{p}<01)$.

\subsection{Relationship between dimensions of PSS and PWB}

(a). Relationship between Significant other dimension of PSS and dimensions of PWB: The Sig other dimension of PSS was found significantly correlated to all aspects of PWB, the highest being with positive relations $(.35, \mathrm{p}<.01)$ followed by self acceptance $(.25, \mathrm{p}<.01)$ and the lowest was with positive growth $(.13, \mathrm{p}<.05)$.

(b). Relationship between Friends dimension of PSS with aspects of PWB: The friends dimension of PSS too was significantly correlated with all aspects of $\mathrm{PWB}(\mathrm{p}<.01)$. The highest relationship was found with positive relations $(.40, \mathrm{P}<.01)$ and the lowest was with environmental mastery $(.14, \mathrm{p}<.01)$.

(c). Relationship between Family dimension of PSS with aspects of PWB: The family dimension of PSS was significantly related to all aspects of PWB except with personal growth. The family dimension correlated the highest with self acceptance (.30, p<.01) aspect of PWB followed by an almost equal value in positive relations $(.29, \mathrm{p}<.01)$. Its lowest relation was with autonomy $(.15$, $\mathrm{p}<.01)$.

Overall, all three dimensions PSS viz., significant other, friends and family were found positively and significantly related to all aspects of PWB (except between family dimension of PSS and personal growth of PWB). The trend of results further suggest that all the dimensions

of PSS are highly and consistently related to positive relations dimension of PWB indicating that individuals high on PSS are more likely to experience better Positive relations. These results are along the expected lines and are also in agreement with research literature.

\section{Linear regression analysis}

Linear regression analyses were conducted to determine the effect of perceived social support on PWB for the total sample and separately for males and females as gender variance was observed in the relationship of each of these samples with PWB. 
Perceived Social Support and Psychological Well-Being: Testing the Unique Association and Gender Differences among Young Working Adults

Table 3, Summary of results of regression of PSS on PWB by Gender

\begin{tabular}{|c|c|c|c|c|c|c|c|c|}
\hline \multirow{2}{*}{$\begin{array}{l}\text { Dependent } \\
\text { variable }\end{array}$} & \multirow[t]{2}{*}{ Gender } & \multirow[t]{2}{*}{$\mathbf{R}$} & \multirow[t]{2}{*}{$\mathbf{R}^{2}$} & \multirow{2}{*}{$\begin{array}{l}\text { Adj } \\
R^{2}\end{array}$} & \multirow{2}{*}{$\begin{array}{l}\text { F } \\
\text { (sig) }\end{array}$} & \multicolumn{3}{|c|}{ Beta values } \\
\hline & & & & & & Friends & Family & PSS \\
\hline \multirow{3}{*}{ PWB } & Male & .416 & .173 & .159 & $11.806(\mathrm{p}<.01)$ & .080 (ns) & $-.114(\mathrm{~ns})$ & $.429(\mathrm{p}<.05)$ \\
\hline & Female & $.337^{\mathrm{a}}$ & .114 & .089 & $4.653(\mathrm{p}<.01)$ & .132 (ns) & $.269(\mathrm{p}<.05)$ & $-.028(\mathrm{~ns})$ \\
\hline & $\mathrm{M}+\mathrm{F}$ & $.342^{\mathrm{a}}$ & .117 & .108 & $12.464(\mathrm{p}<.01)$ & $.122(\mathrm{~ns})$ & .025 (ns) & $.218(\mathrm{~ns})$ \\
\hline \multirow[t]{3}{*}{ Aut } & Male & $.279^{\mathrm{a}}$ & .078 & .062 & $4.765(\mathrm{p}<01)$ & .118 (ns) & $-.104(\mathrm{~ns})$ & .241 (ns) \\
\hline & Female & $.189^{\mathrm{a}}$ & .036 & .009 & 1.347 (ns) & -.024 (ns) & .083 (ns) & .138 (ns) \\
\hline & $\mathrm{M}+\mathrm{F}$ & $.232^{\mathrm{a}}$ & .054 & .044 & $5.360(\mathrm{p}<.01)$ & .082 (ns) & $-.042(\mathrm{~ns})$ & .190 (ns) \\
\hline \multirow[t]{3}{*}{ E M } & Male & $.230^{\mathrm{a}}$ & .053 & .036 & $3.156(\mathrm{p}<.05)$ & -.030 (ns) & -.093 (ns) & .319 (ns) \\
\hline & Female & $.283^{\mathrm{a}}$ & .080 & .055 & $3.155(\mathrm{p}<.05)$ & $-.059(\mathrm{~ns})$ & $.344(\mathrm{p}<05)$ & $-.053(\mathrm{~ns})$ \\
\hline & $\mathrm{M}+\mathrm{F}$ & $.194^{\mathrm{a}}$ & .038 & .027 & $3.684(\mathrm{p}<.05)$ & $-.010(\mathrm{~ns})$ & .075 (ns) & .047 (ns) \\
\hline \multirow[t]{3}{*}{ PG } & Male & $.212^{\mathrm{a}}$ & .045 & .028 & 2.639 (ns) & .081 (ns) & $-.170(\mathrm{~ns})$ & .232 (ns) \\
\hline & Female & $.237^{\mathrm{a}}$ & .056 & .030 & 2.161 (ns) & .126 (ns) & .131 (ns) & .097 (ns) \\
\hline & $\mathrm{M}+\mathrm{F}$ & $.174^{\mathrm{a}}$ & .030 & .020 & $2.918(\mathrm{p}<.05)$ & .099 (ns) & -.074 (ns) & .129 (ns) \\
\hline \multirow[t]{3}{*}{ Pos R } & Male & $.514^{\mathrm{a}}$ & .264 & .251 & $20.208(\mathrm{p}<.01)$ & .115 (ns) & $-.214(\mathrm{~ns})$ & $.558(\mathrm{p}<01)$ \\
\hline & Female & $.404^{\mathrm{a}}$ & .163 & .140 & $7.094(\mathrm{p}<.01)$ & .123 (ns) & .230 (ns) & .101 (ns) \\
\hline & $\mathrm{M}+\mathrm{F}$ & $.437^{\mathrm{a}}$ & .191 & .183 & $22.224(\mathrm{p}<.01)$ & .148 (ns) & -.051 (ns) & $.346(\mathrm{P}<.01)$ \\
\hline \multirow[t]{3}{*}{ PIL } & Male & $.271^{\mathrm{a}}$ & .073 & .057 & $4,455(\mathrm{p}<.01)$ & .139 (ns) & .024 (ns) & .129 (ns) \\
\hline & Female & $.262^{\mathrm{a}}$ & .069 & .043 & $2.688(\mathrm{p}<.05)$ & .121 (ns) & .253 (ns) & -.095 (ns) \\
\hline & $\mathrm{M}+\mathrm{F}$ & $.223^{\mathrm{a}}$ & .050 & .040 & $4.940(\mathrm{p}<.01)$ & .135 (ns) & .086 (ns) & .031 (ns) \\
\hline \multirow[t]{3}{*}{$\overline{\mathrm{SA}}$} & Male & $.434^{\mathrm{a}}$ & .188 & .174 & $13.065(\mathrm{p}<.01)$ & -.065 (ns) & .023 (ns) & $.465(\mathrm{P}<.01)$ \\
\hline & Female & $.295^{\mathrm{a}}$ & .087 & .062 & $3.458(\mathrm{p}<05)$ & .276 (ns) & .256 (ns) & $-.232(\mathrm{~ns})$ \\
\hline & $\mathrm{M}+\mathrm{F}$ & $.342^{\mathrm{a}}$ & .117 & .108 & $12.477(\mathrm{p}<.01)$ & .084 (ns) & .131 (ns) & .163 (ns) \\
\hline
\end{tabular}

a. Predictors: (Constant), PSS, Family, Friends

b. Dependent Variable: PWB, Autonomy, Envt mastery, Personal growth, Positive relations, Purpose in life, Self acceptance

ns=not significant 


\subsection{Regression of PSS on PWB as dependent variable}

It may be observed from the table that PSS, friends and family (total sample) together explained $11.7 \%$ of the variance in PWB. The regression model was significant indicating that PSS has a significant impact on PWB. However, PSS has a higher contribution (Beta=.218) to the prediction of PWB as compared to friends (Beta $=.122$ ) and family (Beta=.025), however, none of the Beta coefficients were individually significant.

Separate regression analysis results of males and female samples revealed that even though the model was significant in both the samples as well, relatively higher proportion of variance in PWB was explained in male sample (17.3\%) as compared to female sample (11.4\%). Regression $\left(\mathrm{R}^{2}\right)$ values are generally considered as a measure of effect size with $\mathrm{R}^{2}$ values of .02 , .15, and .35 representing small, medium, and large effect sizes respectively (Cohen, 1988). To that extent the results of regression analysis point to that PSS explained medium variance in PWB for males and smaller variance for females. The results further showed that while PSS total score contributed significantly towards prediction in male sample (Beta $=.429, \mathrm{p}<.01$ ), it was family dimension which contributed significantly towards prediction in female sample $(.269, \mathrm{p}<.05)$.

\subsection{Regression of PSS on dimensions of PWB as dependent variables}

Positive relations ((19.1\%) and self acceptance (11.7\%) were predicted better with PSS as compared to other dimensions of PWB. The proportion of variance explained in other dimensions of PWB was very less, viz., autonomy (5.4\%), purpose in life (5\%), environmental mastery (3.8\%) and personal growth (3\%). The amount of variance explained in positive relations dimension was in fact better (19.1\%) than that in overall PWB itself (11.7\%) with PSS. Interestingly, none of the dimensions of PSS, viz., significant other, friends and family, contributed significantly towards prediction of overall PWB or its dimensions.

Among males, PSS has explained highest variance in positive relations (26.4\%), followed by self acceptance (18.8\%) and overall PWB (17.3\%). The amount of variance explained in other dimensions is comparatively less, viz., autonomy (7.8\%), personal growth (7.3\%), environmental mastery (5.3\%) and personal growth (4.5\%). The trend of results is by and large the same in female sample. Among females too, the amount of variance explained is highest in positive relations dimension (16.3). This was followed by self acceptance (8.7\%) and environmental mastery (8\%). Relatively lower explained dimensions with PSS were purpose in life (6.9\%), personal growth (5.6\%) and autonomy (3.6\%).

\section{DISCUSSION}

1. The present study was conducted to examine the association between social support and psychological well-being among young working adults and the gender differences in this relationship. The results revealed that the young working adults participated in this study reported above average mean values on all the variables of the study. The results of the present 


\section{Perceived Social Support and Psychological Well-Being: Testing the Unique Association and Gender Differences among Young Working Adults}

study are consistent with means for the overall score of PSS and for three individual subscales of family, friends and the significant other obtained in a study conducted on 154 college students (Females=122; Males=32) by Gregory D. Zimet et al (1988). Also, as argued in a study by Okun \& Keith (1998) the type of support may have differing age-dependent effects, the support perceived from family was higher as compared to the support obtained from friends and significant other by both males and female young working adults in the present study.

Result of the study showed significant difference between males and females in PSS with females reporting high PSS than males indicating that females perceived significantly more social support as compared with males counterparts. The results are in agreement with research studies wherein women reported more perceived support than men (Ross \& Mirowsky, 1989, Cashwell, 1995, Kendler et al., 2005, Sharir et al., 2007). The result that women perceived significantly more support from family and friends than men too are in agreement with the literature that females perceived more social support from their friends than their male counterparts (Cumsille and Epstein, 1994; Chun \& MacDermid 1997; Colarossi, 2001, Eberhart \& Hammen , 2006).

Results also indicated that there were no significant gender differences in PWB and its subdimensions, except in personal growth. The non-significant differences between men and women in PWB and its sub-dimensions is also in line with available literature (Donovan \& Halpern, 2002; Helliwell, 2003).

The results of correlation analysis showed a moderate significant positive relationship between PSS and PWB. The regression model too was found significant suggesting that a high perception of social support is associated with high PWB indicating that PSS has a significant impact on PWB. This result of significant association between social support and PWB is in line with the results of latest research studies (Shakespeare-Finch \& Julie 2013; Liu, Li, Xiao, \& Feldman, 2013; Gülaçtı 2010). The results further showed that while over all PSS score contributed significantly towards prediction in male sample, it was family dimension which contributed significantly towards prediction in female sample. The results provide support for the findings of research studies wherein it was found that family and friends are the individuals' first source of reference and thus have significant influence on life outcomes (Steinberg \& Darling, 1994; Cutrona, 1994). This research was found truer in respect of females.

Positive relations and self acceptance were predicted better with PSS as compared to other dimensions of PWB. This was found true for both males and females. The higher relationship between social support and positive relations is on expected lines and also in agreement with latest research (Ferguson and Goodwin, 2010; Friedman, 2012). The study by Ryan \& Deci (2001) also supported the importance of positive relationships to experience wellbeing. Perceived social support to that extent has emerged as a useful variable as it predicts positive 


\section{Perceived Social Support and Psychological Well-Being: Testing the Unique Association and Gender Differences among Young Working Adults}

relations dimension of PWB. Similarly, social support was found important in predicting self acceptance dimension of PWB which is an essential criteria for maintaining ones self-esteem and self knowledge (Keyes, Ryff \& Shmotkin, 2002).

\section{IMPLICATIONS OF THE STUDY}

The findings of the present study provide empirical evidence about the importance of perceived social support for psychological well-being among young working adults suggesting that higher perception of social support contributes to higher PWB. Towards that end, the present study is valuable in suggesting for design of programs at school/college level to foster social support networks which may help youngsters improve their ability to face the challenges they encounter in their jobs and also maintain their overall well being. Though personality is generally attributed to play a role for people to form and sustain inter-personal relations, there is ample research which shows that such social skills can also be taught through custom-made programs.

\section{LIMITATIONS OF THE STUDY}

The present study was conducted with selective sample of employed adults who were in the process of looking for new jobs. However, there is a need to test this model on a nationally representative sample of young working adults to generalize the finding of current study.

\section{DIRECTION FOR FUTURE RESEARCH}

The present study has provided support for the effectiveness of social support in maintaining positive relations, an important dimension of PWB. Conventional social support is thought of as taking place most often within established, multi-dimensional, and primarily dyadic close personal relationships (Cutrona \& Suhr, 1992; Leatham \& Duck, 1990). However, in growing numbers, social support is being exchanged via computer-mediated communication (on-line) among people who do not know each other and do not communicate face to face. There is a definite need to undertake a study to investigate the impact of such wider social network interactions beyond the immediate inter personal relations to get a full view about the role of social support in the wellbeing.

\section{CONCLUSION}

The findings of this study indicate that although males and females did not differ significantly in terms of PWB, they did differ in terms of perceived social support. Females perceived higher social support than males and females also scored higher in social support from family and friends than their counterparts. Besides, the study also found that family support was the highest form of perceived social support for both young males and females studied in the present research.

The results of the study have also shown that there is a positive and significant relationship between PSS and PWB indicating that the higher the level of perceived social support, the 


\section{Perceived Social Support and Psychological Well-Being: Testing the Unique Association and Gender Differences among Young Working Adults}

better is the PWB of young working adults. Besides, PSS predicted PWB and its dimensions better among males than in females. In addition, perceived social support from family played a more important role in determining PWB for females while overall perceived social support was found contributing to PWB among males. The results also revealed that perceived social support is of greater importance for positive relations and self acceptance aspects of PWB for both males as well as females.

In summary, the research evidence shows that females perceived significantly higher social support as compared to males. However, support from family was perceived as highest source of social support among both males and females. This research also found that young adults' perception of availability of social support influences their PWB. However, the extent of relationship between PSS and PWB seemed to vary with each gender.

\section{Acknowledgments:}

I wish to thank all the respondents without whom this study would not have been possible.

\section{REFERENCES}

Abbott, R. A., Ploubidis, G. B., Huppert, F. A., Kuh, D., Wadsworth, M. E., \& Croudace, T. J. (2006). Psychometric evaluation and predictive validity of Ryff's psychological wellbeing items in a UK birth cohort sample of women. Health and quality of life outcomes, 4,76 .

Arnett, J.J. (2000). Emerging adulthood: a theory of development from the late teens through the twenties .American Psychologist. Retrieved from http://jeffreyarnett.com/articles/ARNETT_Emerging_Adulthood_theory.pdf

Cashwell, C. S. (1995). Family functioning and self-esteem of middle school students: A matter of perspective? Journal of Humanistic Education \& Development, 34, 83-91

Chekki, D. (1996). Family values and family change. Journal of comparative family studies, 27, 409-413.

Chen, X., He, Y., Oliveria, A.M.D., Coco, A.L., Zappulla, C., Kaspar, V., et al. (2004). Loneliness and social adaptation in Brazilian, Canadian, Chinese and Italian children: A multi-national comparative study. Journal of Child Psychology and Psychiatry, 45,8, 1373-1384.

Chun, Y.J. \& MacDermid, S. M. (1997). Perceptions of family differentiation, individuation, and self-esteem among Korean adolescents. Journal of Marriage and the Family, 59, 451-462.

Cohen, J. (1988). Statistical power analysis for the behavioral sciences (rev. ed.). Orlando: Academic Press.

Cohen, S \& Wills, T. A. (1985). Stress, social support, and the buffering hypothesis. Psychological Bulletin, 98, 310-357.

Cohen, S., Underwood, L., \& Gottlieb, B. (2000). Social Support Measurement and Intervention: A Guide for Health and Social Scientists. New York: Oxford University Press.

Colarossi, L. G. (2001). Adolescent gender differences in social support: Structure, function, and provider type. Social Work Research, 25,4, 233. 


\section{Perceived Social Support and Psychological Well-Being: Testing the Unique Association and Gender Differences among Young Working Adults}

Cumsille PE, Epstein N. Family cohesion, family adaptability, social support, and adolescent depressive symptoms in outpatient clinic families (1994). . Journal of Family Psychology. 8:202-214.doi:10.1037/0893-3200.8.2.202.

Cutrona, C. E., \& Suhr, J. A. (1992). Controllability of stressful events and satisfaction with spouse support behaviors. Communication Research, 19, 154-174.

Cutrona, C.E., Cole, V., Colangelo, N., Assouline, S.G. \& Russel, D.W. (1994) 'Perceived Parental Social Support and Academic Achievement: An Attachment Theory Perspective', Journal of Personality and Social Psychology, 66,2, 369-378.

Cyranowski, J. M., Frank, E., Young, E., \& Shear, M. K. (2000). Adolescent onset of the sex difference in lifetime rates of major depression. Archives of General Psychiatry, 57, 2127. doi:10.1001/archpsyc .57.1.21

Dahlem, Nancy W., Zimet, Gregory D \& Walker, Robin R. (1991). The Multidimensional Scale of Perceived Social Support: A confirmation study. Journal of Clinical Psychology, 47,6, 756-761.

Diener, E. (2000). Subjective well-being: The science of happiness and a proposal for a national index. American Psychology, 55,1, 34-43.

Dolan, P., Layard, R. \& Metcalfe, R. (2011), "Measuring Subjective Wellbeing for Public Policy: Recommendations on Measures"., Center for Economic Performance, Special Paper No. 23 March. 6.

Dollete, Steese, Phillips, \& Matthews, (2004). Understanding girls' circle as an intervention on perceived social support, body image, self-efficacy, locus of control and self-esteem. The Journal of Psychology, 90,2, $204-215$.

Donovan, N. and Halpern, D. (2002). Life Satisfaction: the state of knowledge and implications for government. Cabinet Office analytical paper. London: Cabinet Office.

Eberhart NK \& Hammen CL. (2006). Interpersonal predictors of onset of depression during the transition to adulthood. Personal Relationships,13:195-206. doi:10.1111/j.1475 6811.2006.00113.x.

Ferguson, S. \& Googwin, A. (2010).Optimism andWell-Being inOlder Adults: TheMediating Role of Social Support and Perceived Control. The International Journal of Aging and Human Development, 71, 43-68.

Friedman (2012). Wellbeing, ageing and immunity. In Segerstrom (Ed.) The Oxford Handbook of Psychoneuroimmunology. Oxford University Press: New York

Gallagher, E. N., \& Vella-Brodrick, D. A. (2008). Social Support and Emotional Intelligence as Predictors of Subjective Well-Being. Personality and Individual Differences, 44, 15511561. http://dx.doi.org/10.1016/j.paid.2008.01.011

Garber, J., \& Flynn, C.A. (2001). Vulnerability to depression in childhood and adolescence. In R. Ingram \& J. Price (Eds.), Vulnerability to psychopathology: Risk across the lifespan, (pp. 175-225). NY: Guilford.

Gülaçt, F. (2010). The effect of Perceived Social Support on subjective well-being. Procedia Social and Behavioral Sciences, 2,2, 3844-3849.

Helliwell, John F. (2003). How's life? Combining individual and national variables to explain subjective well-being. Economic Modelling, 20,2, 331-360.

Huppert, F.A., Marks, N., Clark, A., Siegrist, J., Stutzer, A., Vittersø, J. \& Wahrendorf J.(2009). Measuring well-being across Europe: Description of the ESS well-being module and preliminary findings. Social Indicators Research. 91(3):301-315. doi: 10.1007/s11205008-9346-0. 


\section{Perceived Social Support and Psychological Well-Being: Testing the Unique Association and Gender Differences among Young Working Adults}

Judge, T. A., Thoresen, C. J., Bono, J. E., \& Patton, G. K. 2001. The job satisfaction-job performance relationship: A qualitative and quantitative review. Psychological Bulletin, 12, 376-407.

Kendler KS, Myers J, Prescott CA. 2005. Sex differences in the relationship between social support and risk for major depression: a longitudinal study of opposite-sex twin pairs. Am. J. Psychiatry, 162:250-256. [PubMed]

Keyes, C. L. M., Shmotkin, D., \& Ryff, C. D. (2002). Optimizing well-being: The empirical encounter of two traditions. Journal of Personality and Social Psychology, 82, 10071022.

Leatham G., Duck S. (1990). Conversations with friends and the dynamics of social support. In Duck S., Silver R. C., editors. (Eds.), Personal relationships and social support (pp. 129). London, UK: Sage

Liu, H., Li, S., Xiao, Q., \& Feldman, M. W. (2013). Social Support and Psychological WellBeing Under Social Change in Urban and Rural China. Social Indicators Research, 119,2, 979-996.

Mahaffy, K. A. (2004). Girls' Low Self-Esteem: How Is It Related to Later socioeconomic Achievements?. Gender and Society, 18,3, 309-327.

Mullatti, l (1992). Changing Profile of The Indian Family. In The Changing Family In Asia: Bangladesh, India, Japan, Philippines, and Thailand, Ed. UNESCO. Bangkok: Principal Regional Office for Asia and The Pacific.

Okun, M. A., \& Keith, V. M. (1998). Effects of positive and negative social exchanges with various sources on depressive symptoms in younger and older adults. Journal of Gerontology, 53, 4-20.

Pugliesi, K., \& Shook, S. L. (1998). Gender, Ethnicity, and Network characteristics: variation in social support resources. Sex Roles, 38, 215-238.

Rindfuss, R. R. (1991). The young adult years: Diversity, structural change, and fertility. Demography, 28, 493512.

Ross, C. E., \& Mirowsky, J. (1989). Explaining the social patterns of depression: Control and problem solving-or support and talking. Journal of Health and Social Behavior, 30, 206219.

Ryan, R.M. \& Deci, E. L (2001). On happiness and human potentials: A review of research on hedonic and eudaimonic well-being. Annual Review of Psychology, 52, 141-166.

Ryff, C. D. (1989). Beyond Ponce de Leon and Life Satisfaction: New Directions in Quest of Successful Ageing. International Journal of Behavioral Development, 12,1, 35-55.

Ryff, C. D., \& Keyes, C. L. (1995). The structure of psychological well-being revisited. Journal of Personality and Social Psychology, 69,4, 719-727.

Sarason, B. R., Sarason, I. G., \& Gurung, R. A. R. (2001). Close personal relationships and health outcomes: A key to the role of social support. In B. R. Sarason, \& S. W. Duck (Eds.), Personal relationships: Implications for clinical and community psychology. United Kingdom: Wiley \& Sons

Sethi, B. B. (1989). Family as a potent Therapeutic force. Indian journal of psychiatry, 31,22-30.

Shakespeare-Finch, J. E., \& Green, J. (2013). Social support promotes psychological well-being following a natural disaster. Australia \& New Zealand Disaster \& Emergency Management Conference. AST Management Pty Ltd. 
Sharir D., Tanasescu M., Turbow D. \& Maman Y. (2007). Social Support And Quality of Life Among Psychiatric Patients In Residential Homes. International Journal of Psychosocial Rehabilitation. 11,1, 85.

Southwick, S.M., Vythilingam, M \& Charney, D.S. (2005). The psychobiology of depression and resilience to stress: Implications for prevention and treatment. Annual Review of Clinical Psychology, 1, 255-91.

Springer, K. W., Hauser, R. M. \& Freese, J. (2006). Bad news indeed for Ryff's six-factor model of well-being. Social Science Research, 35, 1120-1131.

Steinberg, L. and Darling, N. (1994) 'The Broader Context of Social Influence in Adolescence', In Silbereisen, R.K. \& Todt, E. (Eds.), Adolescence in Context: The Interplay of Family, School, Peers, and Work in Adjustment. New York: Springer-Verlag Inc.

Vermeulen, M., \& Mustard, C. (2000). Gender differences in job strain, social support at work,and psychological distress. Journal of Occupational Health Psychology, 5,4, 42840. DOI: DOI:10.1037//0022-3514.82.6.1007

Vlajković, J.(1992). Životne krize i njihovo prevazilaženje. Nolit: Beograd. http://dx.doi.org/10.1111/j.2044-8325.1995.tb00585.x

Walen, H. R., \& Lachman, M. E. (2000). Social Support and Strain from Partner, Family, and Friends: Costs and Benefits for Men and Women in Adulthood. Journal of Social and Personal Relationships, 17,1, 5-30.

Whitney, C. (2010). Social supports among college students and measures of alcohol use , perceived stress , satisfaction with life, EI and coping. Journal of Student Wellbeing, 4,1, 49-67.

Zimet, G.D., Dahlem, N.W., Zimet, S.G., \& Farley, G.K. (1988). The Multidimensional Scale of Perceived Social Support. Journal of Personality Assessment, 52, 30-41. 